\title{
Insufficient physical activity level among Sahrawi adults living in a protracted refugee setting
}

\author{
Eivind Andersen ${ }^{1 *}$ DD, Ida Kjellså2 ${ }^{2}$ Victoria Telle Hjellset ${ }^{2}$ and Sigrun Henjum²
}

\begin{abstract}
Background: The Sahrawi people fled their homes in 1975 as the conflict in Western Sahara escalated and settled down near Tindouf, Algeria, where they still live. High prevalence of overweight and obesity and type 2 diabetes had been found in this protracted refugee setting. Scaling up national policy efforts to promote physical activity (PA) is critical to reducing the prevalence of noncommunicable diseases (NCDs) in the near future. One possible barrier to the inclusion of PA in NCD prevention strategies is the lack of research on PA level, which may reduce political support and policy development for PA. Thus, the aim of this study was to investigate the PA level among adults living in Sahrawi refugee camps and socioeconomic factors associated with PA.
\end{abstract}

Methods: A cross-sectional survey was carried out in 2014 in five refugee camps near Tindouf, Algeria. A total of 180 women and 175 men were included. PA was measured using the international physical activity questionnaire short form (IPAQ-SF).

Results: There was a large amount of variance in reported PA for both genders, ranging from 10 min of total PA per week to above $40 \mathrm{~h}$. Forty-three percent of the participants had a low PA level (defined as not meeting the PA recommendations of 150 min of moderate to vigorous PA per day). The chi-square test of independence showed that males, those aged $\geq 60$ years and people with higher education were more likely to be in the low PA level category. No significant relationship was found between PA level and BMI status. Most of the participants thought that engaging in PA would be wise, valuable, right and good but thought to a lesser degree that PA would be easy, comfortable and interesting.

Conclusions: Almost half of the participants were categorised as insufficiently physically active, however, most of the Sahrawi refugees express a positive attitude towards PA. PA is a low-cost approach to reducing deaths and NCDs, government initiatives to increase PA levels in refugee camps are advised.

Keywords: Sahrawi refugees, Physical activity, IPAQ, Public health

\footnotetext{
* Correspondence: eivind.andersen@usn.no

${ }^{1}$ Faculty of Humanities, Sports and Educational Science, University of South-Eastern Norway, PO box 235, 3603 Horten, Kongsberg, Norway

Full list of author information is available at the end of the article
} 


\section{Background}

Western Sahara is a conflicted region to which both Morocco and the Sahrawi people claim rights [1]. The armed struggle between the two parties forced thousands of Sahrawi's to flee east over the border to Algeria in 1975. The Sahrawi refugees settled down in refugee camps in the Tindouf Province in Algeria, where they still live. The harsh desert environment makes the refugees dependent on food aid. Monthly they receive basic food rations with dry foods as well as fresh foods such as fruit and vegetables from the international community [2]. In addition, food is sold in local shops, but the selection is scarce [2]. Furthermore, a study by Morseth et al. (2017) found that only $1 / 3$ of the refugees had adequate dietary diversity [3]. The camps differs from the majority of other refugee camps in which camp life is organised by the refugees themselves, with little outside interference [1].

Grijalva-Eternod et al. (2012) found a coexistence of undernutrition and overweight in this protracted refugee setting, with $25 \%$ of the refugee households affected by the double burden of malnutrition [4]. Furthermore, $53.7 \%$ of the women were classified as overweight or obese, and $71.4 \%$ had central obesity. The reasons for this high prevalence of overweight and obesity are not known, but suggested factors are cultural associations between a large body and wealth and beauty [5] and excessive sugar consumption [6]. In addition, urban Sahrawi women with high body mass index (BMI) values have been found to walk significantly less than those with normal BMI values, thereby reducing their energy expenditure [6]. Additionally, a high prevalence of type 2 diabetes (T2D) and prediabetes has been found among Sahrawi refugees [7], and numbers are expected to rise in the near future (Henjum et al. 2020, in press).

Physical activity (PA) has consistently been shown to be independently associated with a lower risk of a range of chronic noncommunicable diseases (NCDs) $[8,9]$ and has been a primary focus of public health guidelines for many years $[9,10]$. PA is also a cornerstone in the prevention and management of overweight and obesity [11], which are strongly linked to the risk of T2D [12], cardiovascular diseases (CVDs) [13, 14] and overall mortality [15]. The extent of change in CVD risk factors in response to a lifestyle intervention is related to the extent of body weight loss [16], and loss of body fat is likely to be an important mediator between changes in PA and changes in risk factors for cardiometabolic diseases [17]. However, an increase in PA has been shown to change biomarkers of cardiometabolic risk without resulting in a concomitant reduction in body weight [18].

Almost three-quarters of all NCD deaths occur in lowand middle-income countries (LMICs) [19]. This reflects the epidemiologic transition from infectious to chronic diseases in LMICs [20]. In 2011, a United Nations (UN) summit put NCDs on the global agenda and called for an international response to address the burden of these diseases throughout all parts of the world, particularly LMICs [21]. Following the UN summit, the World Health Organization (WHO) developed a global monitoring framework to enable global tracking of progress in preventing and controlling NCDs [22]. Physical activity was one of the nine targets outlined in the framework and provides a strong mandate for addressing PA globally. Scaling up national policy efforts to promote PA is critical to reducing the prevalence of NCDs in LMICs and achieving the targets set by the WHO [22]. One possible barrier to the inclusion of PA in NCD prevention is the lack of research evidence on PA levels in LMICs and thus among Sahrawi refugees, which may reduce political support and policy development for PA. Thus, the aim of this study was to investigate the type and amount of PA among adults living in Sahrawi refugee camps and factors associated with PA.

\section{Methods \\ Study design and sample}

A cross-sectional survey was carried out in September and October 2014 in five refugee camps near Tindouf, Algeria. The total population in all five camps was estimated to be approximately 165,000 . In the present study, the eligible population were all adults, both males and females, above 18 years of age living in one of the five refugee camps: Smara, El Aiune, Ausserd, Dakla and Boujdor. Individuals that were sick, bedridden or due to some reason unable to answer questions were excluded from the study.

The sample size was chosen based on an estimated prevalence of an inadequate PA level (i.e., not meeting the WHO recommendations of at least $150 \mathrm{~min}$ of moderate-intensity PA throughout the week, or at least 75 min of vigorous-intensity PA throughout the week, or an equivalent combination of moderate- and vigorousintensity activity (MVPA) [23]) of 50\% and an absolute precision of $5 \%$ for the $80 \%$ confidence interval [24] Assuming incomplete sampling from $10 \%$ of the participants, we calculated a final desired sample size of 180 men and 180 women, as determined with Open Source Epidemiologic Statistics for Public Health (OpenEpi). Due to the unequal number of inhabitants in the five camps, a probability proportional to size (PPS) method was used to select participants from each camp [3]. We assumed a 50/50 gender balance in all the camps. This resulted in an estimated sample of 51, 51, 38, 23 and 17 persons of each gender from Smara, El Aiune, Ausserd, Dakla and Boujdor, respectively [3]. During the study period, 52 participants withdrew mainly due to work obligations or personal or family illness, and two participants were excluded. Forty-nine additional participants 
were randomly recruited, so that the final sample consisted of 355 participants: 175 men and 180 women. Three hundred three participants reported some form of PA and are thus included in the PA analysis.

A three-staged cluster sampling was performed. The first stage was to select camps (PPS) and the second stage was to select households. They were randomly selected by tossing a pen in order to decide the direction in which the research team was to drive upon leaving the dispensaries. The team drove toward the boarder of the camp and each seventh household was selected. The third stage was to randomly select one man and one woman from each household. If more than one man or woman in the household was eligible and wished to participate, numbers were assigned to each person. A fieldworker then pointed to a piece of paper with numbers in random order and the person who matched the selected number was included. In households where men were not present, the woman was included and a man in the neighboring household was asked to participate.

\section{Measurements \\ Physical activity}

The international physical activity questionnaire short form (IPAQ-SF) [25] was used to assess PA. Local field workers fluent in English, Spanish or Hassania (the local language) interviewed the participants in their own homes. All field workers were trained in interview technique over a 7 days period, including 2 days for conducting a pilot study. The researchers oversaw all interviews. After the interview the researcher checked the answers and asked both the interviewer and the participant some control questions to make sure that the interviewer had asked the questions in the right manner and that the participant had understood the questions. The IPAQ focuses on the amount of PA performed over the past 7day period. The IPAQ includes questions about the time spent engaging in vigorous PA, moderate PA and walking in 10-min bouts or longer. Within these domains, participants are asked to consider all types of physical activities, including activities performed during leisure time, domestic and gardening activities, work-related activities and transport-related activities. Relevant examples of activity performed at the different intensities were mentioned in the items. The data obtained from the IPAQ were used to estimate the total amount of PA completed in a 7-day period by weighting the reported min per week in each domain by a metabolic equivalent (MET) energy expenditure estimate. The weighted MET minutes per week were then calculated by multiplying the duration (minutes), frequency (days) and MET intensity and then summing the three domains, namely, vigorous (8 METs), moderate (4 METs) and walking (3.3 METs), to produce a weighted estimate of total PA per week (min.week ${ }^{-1}$ ) [25]. The participants were categorised into three PA levels according to the IPAQ scoring criteria: Low (category 1): meets neither moderate nor high criterion. Moderate (category 2): meets any of the following three criteria: (a) three or more days of vigorous-intensity activity of at least $20 \mathrm{~min} \cdot \mathrm{day}^{-1}$, (b) five or more days of moderate-intensity activity and/or walking of at least $30 \mathrm{~min} \cdot \mathrm{day}^{-1}$, and (c) five or more days of any combination of walking, moderate-intensity, or vigorous-intensity activities achieving a minimum of at least $600 \mathrm{MET} \cdot \mathrm{min} \cdot \mathrm{week}^{-1}$. High (category 3): meets any one of the following two criteria: (a) vigorousintensity activity on at least 3 days and accumulating at least $1500 \mathrm{MET} \cdot \mathrm{min} \cdot \mathrm{week}^{-1}$ and (b) seven or more days of any combination of walking, moderate intensity, or vigorous-intensity activities accumulating at least 3000 MET.min.week ${ }^{-1}$. Those categorised as having moderate or high activity were classified as being sufficiently active according to the WHO PA guidelines [23]. Data cleaning and processing were carried out in accordance with the guidelines published by the IPAQ Research Committee, and the methods used to score the IPAQ are described in the IPAQ scoring protocol [26]. Additional questions (supplementary material online), including views of one's own PA level on a 5-point scale $(0=$ far too low, $1=$ slightly too low, $2=$ satisfying, $3=$ slightly too high and $4=$ far too high), views regarding engaging in PA on a 3point scale (e.g. $0=$ silly, $1=$ neutral, $2=$ wisely), what activities they usually engaged in, what they liked to do, and organised physical activities they would like to be arranged in the camps, were included in the questionnaire.

\section{Anthropometric measures}

Weight was measured with the participants in light clothing using digital Tara scales produced for UNICEF (SECA 890; SECA, Hamburg, Germany). Participants' height, without shoes, was measured to the nearest 0.1 $\mathrm{cm}$ using an ultrasonic metre from Soehnle Professional (Backnang, Germany) or a UNICEF portable stadiometer if the participant had a similar or taller height than the field worker performing the measurements. Waist circumference was measured by trained personnel midway between the hipbone and lowest rib using an ergonomic measuring tape from SECA (SECA 201; SECA). A waist circumference $\geq 80 \mathrm{~cm}$ and $\geq 94 \mathrm{~cm}$, for women and men respectively, was considered high [27]. BMI was calculated as body weight divided by squared body height $\left(\mathrm{kg}^{\prime} \mathrm{m}^{-2}\right)$.

\section{Statistical analysis}

All statistical analyses were performed using SPSS (Statistical Package for the Social Sciences for Windows, version 26, IBM, Inc., Chicago, IL, USA). Continuous variables are presented as medians and interquartile 
ranges (IQRs) since they were not normally distributed, and categorical variable are presented as percentages. Differences between groups were assessed by the MannWhitney U test for continuous variables and Pearson's chi-squared test for categorical variables. Associations between sociodemographic (gender (man/woman), age (18-59/60-90), education (up to 6th grade/7 to 9th grade/10 to 12 th grade/higher education), marital status (married/not married), work status (paid work/not paid work) and anthropometric factors (BMI (underweight/ normal weight/overweight/obese)) and low PA level (category 1 in IPAQ) were assessed with multivariable logistic regression, with low PA level as the dependent variable. All significance tests were two-sided.

\section{Ethics}

Ethics approval for the survey was given by the Regional Committees for Medical and Health Research Ethics in Norway (ref. 2014/1155) and by the Saharawi Ministry of Public Health.

Informed consent was obtained from all participants both orally and in writing. It was emphasised that refusal to participate or withdrawal from the survey would not have any negative consequences for the participants. The study was conducted according to the guidelines provided in the Declaration of Helsinki.

\section{Results}

The distribution of the 350 included participants were: Boujdor $n=35$, Ausserd $n=74$, El Aiune $n=104$, Dakhla $n=42$ and Smara $n=100$. Table 1 displays the relevant sociodemographic and anthropometric information for both women and men. Most of the refugees were born in the camp or had been living there since the refugee camps were set up in 1975/76. Those who had not been born in the refugee camp had been living there for a median (IQR) of 36.0 (15) years and 31.0 (24) years for women and men, respectively. A considerably larger number of women were overweight or obese than men (64.5 and $25.1 \%$, respectively). While more than half of the men had paid work (army, construction worker, taxi driver, salesperson), very few women had paid work (kindergarten, nurse, teacher, nanny, secretary, cleaning). A total of $85.6 \%$ of the women and $89.1 \%$ of the men had some income (mostly from other members of the

Table 1 Sociodemographic and anthropometric characteristics for women and men living in Sahrawi refugee camps in Algeria ( $n=$ 355). Data are median (IQR) or percent

\begin{tabular}{|c|c|c|c|}
\hline Characteristic & Women $(n=180)$ & Men $(n=175)$ & $P$ value \\
\hline Age (years) & $40.0(23)$ & $38.0(32)$ & 0.59 \\
\hline Height (cm) & $157.0(8.4)$ & $168.5(10.0)$ & $<0.01$ \\
\hline Weight (kg) & $66.7(19.5)$ & $60.7(18.8)$ & $<0.01$ \\
\hline $\mathrm{BMI}\left(\mathrm{kg}^{-2} \mathrm{~m}^{-2}\right.$ & $26.9(7.3)$ & $21.6(6.1)$ & $<0.01$ \\
\hline \multicolumn{4}{|l|}{ BMl categories } \\
\hline$-<18.5 \mathrm{kgm}^{-2}(\%)$ & 2.2 & 18.9 & \\
\hline - 18.5 to $24.9 \mathrm{kgm}^{-2}(\%)$ & 33.3 & 56.0 & \\
\hline - 25.0 to $29.9 \mathrm{kgm}^{-2}(\%)$ & 31.7 & 20.0 & \\
\hline$-\geq 30 \mathrm{kgm}^{-2}(\%)$ & 32.8 & 5.1 & $<0.01$ \\
\hline Waist circumference $(\mathrm{cm})$ & $91.0(18.6)$ & $79.7(20.3)$ & $<0.01$ \\
\hline - Women: $\geq 80 \mathrm{~cm}$, Men: $\geq 94 \mathrm{~cm}(\%)$ & 75.0 & 20.6 & \\
\hline \multicolumn{4}{|l|}{ Education level (\%) } \\
\hline - None & 32.2 & 27.4 & \\
\hline - Up to 6th grade & 27.2 & 18.9 & \\
\hline - 7 th to 9 th grade & 25.0 & 28.6 & \\
\hline - 10 th to 12 th grade & 12.2 & 19.4 & \\
\hline - Higher education & 3.3 & 5.7 & 0.09 \\
\hline Married (\%) & 59.4 & 55.4 & 0.44 \\
\hline Paid work (\%) & 13.3 & 54.3 & $<0.01$ \\
\hline Number of children & $3.0(4)$ & $1.0(5)$ & 0.01 \\
\hline People living in household & $6.0(4)$ & $7.0(4)$ & 0.03 \\
\hline Born in camp or lived there since the beginning in 1975/76 (\%) & 92.8 & 80.0 & 0.001 \\
\hline
\end{tabular}

Abbreviations: IQR Interquartile range; CI Confidence interval; BMI Body mass index 
household). There were no differences between genders with regard to education level or marital status.

Of the total sample of 355 participants, 303 reported some form of PA and are thus included in the PA analysis below. Compared to those who reported some form of PA, those who did not report any PA $(n=52)$ where older (median (IQR) 37.0 (26) years vs. 56.5 (34) years, $\mathrm{U}=4741 ; \mathrm{P}<0.01$ ) had a larger waist circumference (median (IQR) 85 (20) cm vs. 92 (21) cm, $U=6434 ; P=0.04$ ) and were less educated $(P=0.01)$. Women reported significantly less walking per week, more moderate PA, and less vigorous PA than men did. There were no differences in total PA levels between genders (Table 2). There was a large variance in reported PA for both genders, ranging from $10 \mathrm{~min}$ of total activity time per week to above $40 \mathrm{~h}$, as displayed by the large IQR in Table 2 .

Table 3 shows the associations between sociodemographic and anthropometric factors and low PA, where low PA is defined as having less than half an hour of at least moderate intensity PA on most days. Females, those aged below 60 years and those with a lower education level had a significantly lower odds ratio of having a low PA level than males, those aged 60 years or above and those with a higher education level (Table 3). There were no significant associations of BMI status, marital status or whether the participant had paid work with PA level.

Forty-three percent of the participants had a low PA level (defined as not meeting the PA recommendations of 150 min of MVPA per week) (Fig. 1). The chi-square test of independence showed that males were more likely to be in the low PA level category and less likely to be in the moderate PA level category than females $\left(\mathrm{X}^{2}(2)=\right.$ $11.4, \mathrm{P}<0.01)$ and that those aged 60 or above were significantly more likely to have a low PA level and less likely to have a high PA level than participants under the age of 60 years $\left(\mathrm{X}^{2}(2)=20.2, \mathrm{P}<0.01\right)$ (Fig. 1). No significant relationship was found between PA level and BMI status.
The subjective assessment of one's own PA level showed that $27.8 \%$ of the women believed their PA level was slightly or far too low, $66.1 \%$ states that they were satisfied with their PA level and $6.1 \%$ believed that it was slightly or far too high. For the men, 23.4\% reported that their PA level was slightly or far too low, $62.3 \%$ that it was satisfactory and $14.3 \%$ that it was slightly or far too high. Most of the participants thought that engaging in PA would be wise, valuable, right and good but to a lesser degree that it would be easy, comfortable and interesting (Table 4). There were no significant differences in views regarding engaging in PA between genders.

When asked what PA they preferred $(n=350)$, the most reported activities were walking $(n=209)$, football $(n=57)$, dancing $(n=22)$ and chore-related activities such as cleaning ( $n=35)$ and working $(n=17)$. Almost all of the participants had one or more suggestions regarding activities or sport facilities they would like to be arranged or built to help them become more physically active. The most common suggestions were sports hall (25\%), football groups (24\%), swimming pool (15\%) and walking/running groups (10\%).

\section{Discussion}

To our knowledge, this is the first study to measure PA level in a refugee setting. Almost half of the refugees did not reach the recommended PA level. Males, those aged above 60 years and refugees with higher education had a significantly higher odds ratio of having a low PA level. No significant association between BMI and PA level was found. There was a large variance in reported PA for both genders, ranging from $10 \mathrm{~min}$ of total activity time per week to above $40 \mathrm{~h}$. Women reported significantly less walking min per week, more moderate PA, and less vigorous PA than men. Most of the participants thought that engaging in PA would be wise, valuable, right and good but to a lesser degree that it would be easy, comfortable and interesting. Most of the Sahrawi refugees included in this study were born in the camp or

Table 2 Self-reported physical activity level and energy expenditure for women and men living in Sahrawi refugee camps in Algeria $(n=303)$. Data are median (IQR)

\begin{tabular}{llll}
\hline Physical activity variable & Women $(\boldsymbol{n = 1 5 5 )}$ & Men $(\boldsymbol{n}=\mathbf{1 4 8})$ & $\boldsymbol{P}$-value \\
\hline Walking $($ min.week \\
Walking $($ MET.min.week
\end{tabular}

Abbreviations: IQR Interquartile range; MET Metabolic equivalent; PA Physical activity

${ }^{\text {a }}$ Walking + moderate PA + vigorous PA [26] 
Table 3 Association between sociodemographic and anthropometric factors and low ${ }^{a}$ physical activity level among people living in Sahrawi refugee camps in Algeria. Data are odds ratios (with 95\% Cls) derived from multivariable logistic regression $(n=303)$

\begin{tabular}{llll}
\hline Characteristic & Odds ratio & $\mathbf{9 5 \% ~ C l}$ & $\boldsymbol{P}$-value \\
\hline Female vs. male & 0.46 & 0.25 to 0.86 & 0.01 \\
Age 19-59 vs. $\geq 60$ years & 0.37 & 0.16 to 0.86 & 0.02 \\
BMI categories vs. obese & & & \\
$\quad$ - Underweight & 1.41 & 0.50 to 3.96 & 0.5 \\
- Normal weight & 0.90 & 0.42 to 1.92 & 0.7 \\
- Overweight & 1.55 & 0.71 to 3.38 & 0.2 \\
Education categories vs. higher education & & \\
- Up to 6th grade & 0.29 & 0.14 to 0.58 & $<0.01$ \\
- 7th to 9th grade & 0.36 & 0.19 to 0.68 & $<0.01$ \\
- 10th to 12th grade & 0.26 & 0.13 to 0.52 & $<0.01$ \\
Married vs. not married & 0.71 & 0.42 to 1.21 & 0.22 \\
Paid work vs. no paid work & 1.21 & 0.68 to 2.17 & 0.5 \\
\hline
\end{tabular}

Abbreviations: BMI Body mass index

The model is adjusted for all variables in the respective columns

aLow PA level was defined as those having less than half an hour of at least moderate intensity PA on most days (i.e., category 1, or low) according to the IPAQ scoring protocol [26]

had been living there since the camps were established in 1975/76. Approximately one-third of the participants had no education, and only a few percent had higher education. There was a relatively large difference between genders with regard to both BMI and waist circumference, where $64.5 \%$ of the women and $25.1 \%$ of the men were classified as overweight or obese according to their BMI, and $75 \%$ of the women and $20.6 \%$ of the men had a waist circumference above the recommended level [27]. One possible explanation for the higher BMI and waist circumference in women compared to men might be that women to a larger degree prefer a larger body size [28], because this is associated with richness, health, strength, and fertility [29].

Forty-three percent of the participants were categorised as insufficiently physically active, which is a higher prevalence than what was found in a study including 146 countries (93\% of the world's population) where $23 \%$ were found to be insufficiently physically active [30]. An even lower prevalence of $15 \%$ was found among people living in low-income countries [30]. A significantly lower prevalence of low PA in low-income countries was also found in the PURE study (21\%) [14] and a World Health Survey-based study (28\%) [31]. There might be several reasons for the low PA level among the Sahrawi refugees. The most striking factor may be the harsh desert environment, with extremely hot summers and windy and cold winters, which makes it difficult to be physically active [32]. Another likely significant factor is that more than half the Sahrawi population is considered particularly vulnerable by the UN refugee agency (UNHCR) due to their heavy reliance on humanitarian assistance to access food, water, and other necessities [33], which would most likely make PA a non-prioritised behaviour to engage in. Other factors explaining the low PA level in our sample might be the high unemployment rate, low education level, and the relatively high age [34] and the few recreational activities offered in the camps. Although the participants with a higher education were significantly less physically active than those with less education, these people were mostly employed in sedentary jobs. In contrast to what was found in a study of 122 countries [35], women were less likely to have a low PA level than men. However, our finding is in line with a multinational study including 46 LMICs with over 200,000 participants that also found women to be more physically active than men [36]. A possible explanation might be that the women are responsible for the daily household chores and errands and thus reach the recommended levels of PA through

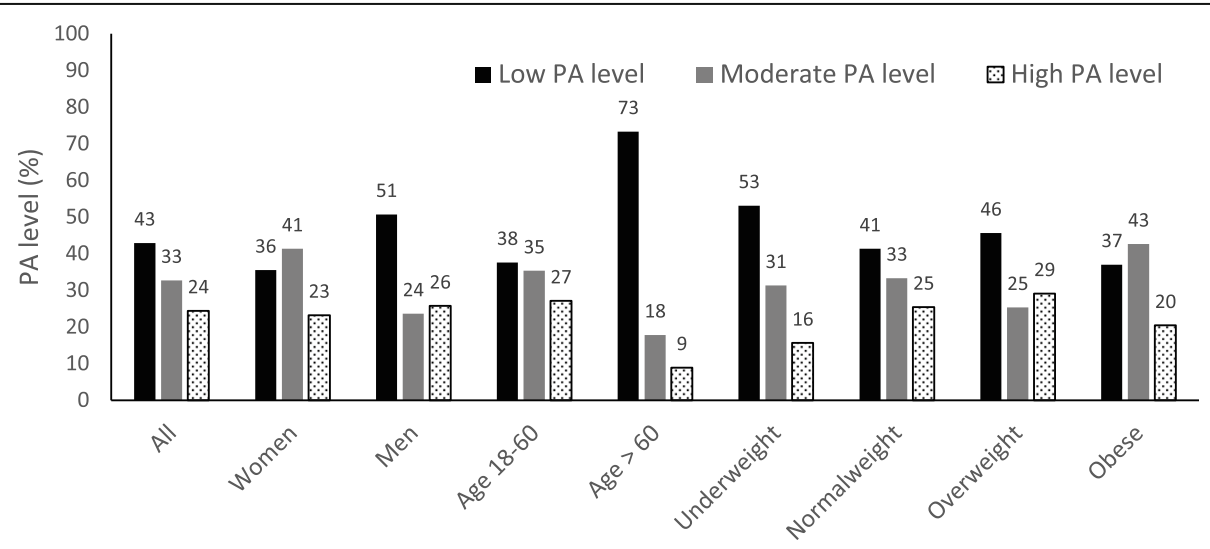

Fig. 1 Distribution of physical activity level by gender, age and weight status $(n=300)$ 
Table 4 The question asked, "Think about yourself being physically active the next 7 days. Is your opinion about this physical activity that it is ..." (Data are percent, $n=302$ )

\begin{tabular}{|c|c|c|c|c|c|}
\hline \multicolumn{3}{|c|}{ Women $(n=180)$} & \multicolumn{3}{|l|}{ Men $(n=175)$} \\
\hline Silly & Neutral & Wisely & Silly & Neutral & Wisely \\
\hline 1.7 & 8.9 & 88.3 & 4.0 & 8.0 & 87.9 \\
\hline Harmful & Neutral & Valuable & Harmful & Neutral & Valuable \\
\hline 3.9 & 5.6 & 90.6 & 4.0 & 5.7 & 89.7 \\
\hline Not necessary & Neutral & Necessary & Not necessary & Neutral & Necessary \\
\hline 4.4 & 16.7 & 78.3 & 8.0 & 13.8 & 77.6 \\
\hline Wrong & Neutral & Right & Wrong & Neutral & Right \\
\hline 0.6 & 6.1 & 92.8 & 1.7 & 8.6 & 89.7 \\
\hline Difficult & Neutral & Easy & Difficult & Neutral & Easy \\
\hline 15.0 & 25.6 & 59.4 & 15.5 & 21.8 & 62.6 \\
\hline Uncomfortable & Neutral & Comfortable & Uncomfortable & Neutral & Comfortable \\
\hline 3.9 & 20.6 & 75.6 & 8.0 & 19.0 & 73.0 \\
\hline Bad & Neutral & Good & Bad & Neutral & Good \\
\hline 2.8 & 9.4 & 87.8 & 1.1 & 10.9 & 87.9 \\
\hline Boring & Neutral & Interesting & Boring & Neutral & Interesting \\
\hline 8.3 & 23.9 & 67.8 & 5.7 & 20.7 & 73.6 \\
\hline
\end{tabular}

these activities. At the same time, men are either unemployed and sit at home with little to do, or if employed, work in jobs that are mostly sedentary. An unexpected finding is that there was no association between PA level and BMI status, which is in contrast to the vast majority of research findings (e.g., [37-39]). Seeing that almost all of the obese participants were women, many of these participants are believed to walk for at least $30 \mathrm{~min}$ on five or more days of the week (PA recommendations using IPAQ) because of their household duties.

CVD is the leading cause of death worldwide [40] and a major economic global burden [41]. While CVD mortality has been reduced in high-income countries, the prevalence of CVD and CVD mortality has increased in low-income countries [42]. As shown in many studies from high-income countries [43], Lear et al. (2017) found in a study on almost 30,000 people from lowincome countries that meeting the WHO PA recommendations was associated with a $22 \%$ lower risk for allcause mortality and a $20 \%$ lower risk of major CVDs than the respective risks associated with not meeting the PA recommendations [14]. The high number of participants in the current study not meeting the PA recommendations is thus a cause of concern. As participating in PA is inexpensive, PA is a low-cost approach to reducing deaths and CVD that is applicable with a large potential effect [14]. Furthermore, the results from Lear et al. (2017) provide robust evidence to support public health interventions to increase all forms of PA in countries with different socioeconomic circumstances [14].
Most of the Sahrawi refugees in our sample report that engaging in PA would be wise, valuable, right and good. In addition, considering the low PA level in this population and the high overweight and obesity rates (especially among women) and thus the increased risk of NCDs putting more pressure on the health system, addressing PA seems appropriate. A systematic review of NCD policies in LMICs concluded that most countries are poorly prepared to tackle the NCD epidemic [44]. Only a few LMICs have developed national policies aimed at reducing NCDs, and even among those with national NCD policies, PA is rarely included [44]. Scaling up national policy efforts to promote PA is critical to reducing the prevalence of NCD in LMICs and achieving the targets set out in the Global Monitoring Framework [45]. There seems to be, however, important barriers to policy implementation that must be overcome before progress in increasing PA can be expected (i.e., PA surveillance, research, resources) [30]. A Lancet review found a small but increasing number of intervention studies from LMICs, and these studies provide initial evidence that community-based interventions can be effective [30]. The authors further conclude that greater implementation of evidence-based interventions could help control NCDs in LMICs [30].

\section{Strengths and limitations}

The main strength of this study is the relatively large, randomly selected sample including both women and men and a high response rate. Our study also has some limitations that need to be addressed. First, the extent to 
which causality can be inferred is lower than that associated with a longitudinal study due to the cross-sectional design used in this study. Second, although the IPAQ-SF is recommended and widely used, validation studies show only a small correlation with objective measures [46]. Most of the studies included in the systematic review found that the IPAQ-SF overestimated PA levels by 36 to $173 \%$ [46]. In a large population-based validation study in Norway, an underestimation of moderateintensity PA and overestimation of vigorous intensity PA were found [47]. Furthermore, the difference between the IPAQ-SF and accelerometer-measured MVPA increased with higher activity and intensity levels and was further affected by male gender, older age and low education level [47]. Although the IPAQ-SF has shown reasonable reliability and can be used to compare PA levels between different populations [25] it has not been validated on this specific population. It is also a weakness of the study that, because of the language barrier, the researcher could not conduct the interviews themselves. However, the researchers oversaw all interviews and control questions were asked to both the interviewers and the participants. The interviewers were also trained for 77 days, and which included a pilot study.

\section{Conclusions}

Almost half of the Sahrawi refugees do not reach the recommended PA level. Males, those aged above 60 years and people with higher education were more likely to be in the low PA level category. Most of the participants expressed a positive attitude towards PA and seeing that PA is a low-cost approach to reducing deaths and CVD, government initiatives to increase PA levels in refugee camps are advised.

\section{Supplementary Information}

The online version contains supplementary material available at https://doi. org/10.1186/s12889-021-10217-w.

\section{Additional file 1.}

\section{Abbreviations \\ PA: Physical activity; NCDs: Noncommunicable diseases; IPAQ- SF: International physical activity questionnaire short form; BMI: Body mass index; T2D: Type 2 diabetes; CVDs: Cardiovascular diseases; LMICs: Low- and middle-income countries; UN: United Nations; WHO: World health Organization; MVPA: Moderate- and vigorous-intensity activity; MET: Metabolic equivalent; IQR: Interquartile range; Cl: Confidence interval; UNHCR: UN refugee agency}

\section{Acknowledgments}

We are grateful to all the women and men participating in this study. Further, we would like to thank the Saharawi Ministry of Public Health for supporting and encouraging this study and the fieldworkers and interpreter for valuable help with the data collection. We are also grateful to the Norwegian Church Aid for supporting and facilitating this work.

\section{Authors' contributions}

Conceptualization: EA, IK, VH, SH. Data curation: EA, IK. Formal analysis: EA. Investigation: EA, IK, VH, SH. Writing - original draft: EA. Writing - review and editing: EA, IK, VH, SH. All authors have read and approved the manuscript.

\section{Funding}

The project received funding from Norwegian Church Aid (https://www. kirkensnodhjelp.no/en/) and the Food and Agriculture Organization of the United Nations (http://www.fao.org/home/en/). The funders had no role in study design, data collection and analysis, decision to publish, or preparation of the manuscript.

Availability of data and materials

Data can be accessed upon request to Eivind.andersen@usn.no.

\section{Ethics approval and consent to participate}

Ethics approval for the survey was given by the Regional Committees for Medical and Health Research Ethics in Norway (ref. 2014/1155) and by the Saharawi Ministry of Public Health.

Informed consent was obtained from all participants both orally and in writing. It was emphasised that refusal to participate or withdrawal from the survey would not have any negative consequences for the participants. The study was conducted according to the guidelines provided in the Declaration of Helsinki.

\section{Consent for publication}

NA.

\section{Competing interests}

The authors declare that they have no competing interests.

\section{Author details}

${ }^{1}$ Faculty of Humanities, Sports and Educational Science, University of South-Eastern Norway, PO box 235, 3603 Horten, Kongsberg, Norway.

${ }^{2}$ Department of Nursing and Health Promotion, Faculty of Health Sciences, Oslo Metropolitan University (OsloMet), Oslo, Norway.

Received: 21 August 2020 Accepted: 11 January 2021

Published online: 19 January 2021

\section{References}

1. HRW, Off the Radar - Human Rights in the Tindouf Refugee Camps. 2014. Available online: https://www.hrw.org/sites/default/files/reports/algeria1014 web.pdf (accessed 31 july 2020).

2. UNHCR, Humanitarian Needs of Sahrawi Refugees in Algeria. 2016-2017. Available online: http://reporting.unhcr.org/sites/default/files/ Humanitarian\%20Needs\%20of\%20Sahrawi\%20Refugees\%20in\%20Algeria\%2 02016-2017\%20-\%20June\%202016.pdf (accessed on 15 July 2020).

3. Morseth MS, et al. Dietary diversity is related to socioeconomic status among adult Saharawi refugees living in Algeria. BMC Public Health. 2017; 17(1):621.

4. Grijalva-Eternod CS, et al. The double burden of obesity and malnutrition in a protracted emergency setting: a cross-sectional study of Western Sahara refugees. PLoS Med. 2012;9(10):e1001320.

5. Rguibi M, Belahsen R. Body size preferences and sociocultural influences on attitudes towards obesity among Moroccan Sahraoui women. Body Image. 2006;3(4):395-400

6. Rguibi M, Belahsen R. Metabolic syndrome among Moroccan Sahraoui adult women. Am J Hum Biol. 2004;16(5):598-601.

7. Carretero-Anibarro E, Hamud-Uedha M. Prevalence of undiagnosed type 2 diabetes mellitus in the sahrawi population of the sahrawi refugee camps of Tindouf, Algeria. Med Clin (Barc). 2019;10:461-2.

8. Schulze MB, et al. Food based dietary patterns and chronic disease prevention. BMJ. 2018;361:k2396.

9. 2018_Physical_Activity_Guidelines_Advisory_Committee. Physical activity guidelines advisory committee scientific report. Washington, DC: U.S. Department of Health and Human Services; 2018. p. 2018.

10. UK_Chief_Medical_Officers, Physical Activity Guidelines. Available online:. https://www.gov.uk/government/publications/physical-activity-guidelinesuk-chief-medical-officers-report (Accessed July 5 2020), 2019. 
11. Zomer $E$, et al. Interventions that cause weight loss and the impact on cardiovascular risk factors: a systematic review and meta-analysis. Obes Rev. 2016;17(10):1001-11.

12. Abdullah $\mathrm{A}$, et al. The magnitude of association between overweight and obesity and the risk of diabetes: a meta-analysis of prospective cohort studies. Diabetes Res Clin Pract. 2010;89(3):309-19.

13. Yatsuya $\mathrm{H}$, et al. Global trend in overweight and obesity and its association with cardiovascular disease incidence. Circ J. 2014;78(12):2807-18.

14. Lear SA, et al. The effect of physical activity on mortality and cardiovascular disease in 130000 people from 17 high-income, middle-income, and lowincome countries: the PURE study. Lancet. 2017;390(10113):2643-54

15. Bhaskaran $\mathrm{K}$, et al. Association of BMI with overall and cause-specific mortality: a population-based cohort study of 3.6 million adults in the UK. Lancet Diabetes Endocrinol. 2018;6(12):944-53.

16. Wing RR, et al. Association of Weight Loss Maintenance and Weight Regain on 4-year changes in CVD risk factors: the action for health in diabetes (look AHEAD) clinical trial. Diabetes Care. 2016:39(8):1345-55.

17. Garcia-Hermoso A, et al. Abdominal obesity as a mediator of the influence of physical activity on insulin resistance in Spanish adults. Prev Med. 2016; 82:59-64.

18. Gill JM, Malkova D. Physical activity, fitness and cardiovascular disease risk in adults: interactions with insulin resistance and obesity. Clin Sci (Lond). 2006; 110(4):409-25.

19. WHO, Global status report on noncommunicable diseases. Available online:. https://apps.who.int/iris/bitstream/handle/10665/148114/9789241564854 eng.pdf? sequence $=1$ (Accessed on August 2 2020), 2014

20. Miranda JJ, et al. Non-communicable diseases in low- and middle-income countries: context, determinants and health policy. Tropical Med Int Health. 2008;13(10):1225-34

21. Milton K, Macniven R, Bauman A. Review of the epidemiological evidence for physical activity and health from low- and middle-income countries. Glob Public Health. 2014:9(4):369-81.

22. WHO, Global action plan for the prevention and control of noncommunicable diseases 2013-2020. Available online:. https://apps.who.int/iris/bitstream/ handle/10665/94384/9789241506236_eng.pdf?sequence=1 (Accessed on August 2 2020), 2013.

23. WHO, Global Recommendations on Physical Activity for Health. Available online:. https://www.who.int/publications/i/item/9789241599979 (Accessed on August 4 2020), 2010.

24. Sullivan, K.M., A.G. Dean, and R.A. Mir, Open Source Epidemiologic Statistics for Public Health. Available online:. https://www.openepi.com/PDFDocs/ SSProporDoc.pdf (Accessed 1 may 2014), 2013.

25. Craig $\mathrm{CL}_{\text {, et }}$ al. International physical activity questionnaire: 12-country reliability and validity. Med Sci Sports Exerc. 2003;35(8):1381-95.

26. IPAQ, Guidelines for Data Processing and Analysis of the International Physical Activity Questionnaire (IPAQ). Short and Long Forms. Available online:. https:// sites.google.com/site/theipaq/scoring-protocol (Accessed 15 may 2020).

27. Alberti $\mathrm{KG}$, et al. Harmonizing the metabolic syndrome: a joint interim statement of the international diabetes federation task force on epidemiology and prevention; National Heart, Lung, and Blood Institute; American Heart Association; world heart federation; international atherosclerosis society; and International Association for the Study of obesity. Circulation. 2009:120(16):1640-5.

28. Naigaga DA, et al. Body size perceptions and preferences favor overweight in adult Saharawi refugees. Nutr J. 2018;17(1):17.

29. Renzaho AM. Fat, rich and beautiful: changing socio-cultural paradigms associated with obesity risk, nutritional status and refugee children from sub-Saharan Africa. Health Place. 2004;10(1):105-13.

30. Sallis JF, et al. Progress in physical activity over the Olympic quadrennium. Lancet. 2016;388(10051):1325-36.

31. Vancampfort D, et al. Physical activity and sleep problems in 38 low- and middle-income countries. Sleep Med. 2018:48:140-7.

32. Tucker $P$, Gilliland J. The effect of season and weather on physical activity: a systematic review. Public Health. 2007;121(12):909-22.

33. UNHCR, Tindouf camps planning figures. Available online:. https://www. unhcr.org/en-Ik/news/press/2018/9/5bae473c4/tindouf-camps-planningfigures.html (Accessed August 15 2020), 2018.

34. Bauman $\mathrm{AE}$, et al. Correlates of physical activity: why are some people physically active and others not? Lancet. 2012;380(9838):258-71.

35. Hallal PC, et al. Global physical activity levels: surveillance progress, pitfalls, and prospects. Lancet. 2012;380(9838):247-57.
36. Koyanagi A, Stubbs B, Vancampfort D. Correlates of low physical activity across 46 low- and middle-income countries: a cross-sectional analysis of community-based data. Prev Med. 2018;106:107-13.

37. Hansen $\mathrm{BH}$, et al. Patterns of objectively measured physical activity in normal weight, overweight, and obese individuals (20-85 years): a crosssectional study. PLoS One. 2013;8(1):e53044.

38. Tudor-Locke C, et al. Accelerometer profiles of physical activity and inactivity in normal weight, overweight, and obese U.S. men and women. Int J Behav Nutr Phys Act. 2010;7:60

39. Hagstromer M, et al. Levels and patterns of objectively assessed physical activity--a comparison between Sweden and the United States. Am J Epidemiol. 2010;171(10):1055-64.

40. Mortality GBD. Causes of Death, Global, regional, and national age-sex specific all-cause and cause-specific mortality for 240 causes of death, 19902013: A systematic analysis for the global burden of disease study 2013. Lancet. 2015;385(9963):117-71.

41. Bloom DE, et al. The global economic burden of noncommunicable diseases. Geneva: World Economic Forum; 2011.

42. Roth $\mathrm{GA}$, et al. Demographic and epidemiologic drivers of global cardiovascular mortality. N Engl J Med. 2015;372(14):1333-41.

43. Nocon M, et al. Association of physical activity with all-cause and cardiovascular mortality: a systematic review and meta-analysis. Eur J Cardiovasc Prev Rehabil. 2008;15(3):239-46.

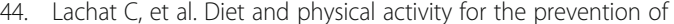
noncommunicable diseases in low- and middle-income countries: a systematic policy review. PLoS Med. 2013;10(6):e1001465.

45. WHO, Global monitoring framework on noncommunicable diseases. Available online:: https://www.who.int/nmh/global_monitoring_framework/en/ (Accessed August 16 2020), 2013.

46. Lee $\mathrm{PH}$, et al. Validity of the International Physical Activity Questionnaire Short Form (IPAQ-SF): a systematic review. Int J Behav Nutr Phys Act. 2011;8: 115.

47. Dyrstad SM, et al. Comparison of self-reported versus accelerometermeasured physical activity. Med Sci Sports Exerc. 2014;46(1):99-106.

\section{Publisher's Note}

Springer Nature remains neutral with regard to jurisdictional claims in published maps and institutional affiliations.
Ready to submit your research? Choose BMC and benefit from:

- fast, convenient online submission

- thorough peer review by experienced researchers in your field

- rapid publication on acceptance

- support for research data, including large and complex data types

- gold Open Access which fosters wider collaboration and increased citations

- maximum visibility for your research: over $100 \mathrm{M}$ website views per year

At BMC, research is always in progress.

Learn more biomedcentral.com/submissions 